$15.39-31.52$ and statistically significant with $p<0.001$ ). The changes observed among control sites were nonsignificant in a statistical sense.

Finally, the proportion of women receiving contraceptives (including referrals or appointments) increased from $6.28 \%$ to $18.55 \%$ (a 12.27 point difference, 95\% CI 2.81-21.72 and statistically significant with $p<0.004)$ as compared to the non-significant changes observed among control sites.

\section{Discussion}

The 4-month intervention proved successful in promoting positive attitudes and in preparing health district directors to guide their respective health team units in continued improvement efforts in addition to making key changes in particular service areas. Specifically, the intervention had a positive impact on:

- Reducing the number of pre-consultation contacts.

- Reducing client waiting times at health facilities.

- Screening more frequently clients' family planning needs.

- Providing more complete information concerning the range of contraceptive options available to women.

- Delivering more frequently the methods upon request. The intervention failed to improve the actual client-provider interaction time, the total number of minutes that clients spend at health facilities, and the quality of services provided to all client profiles analysed.

Weaknesses of this study include the lack of comparability of service quality scales, making results difficult to compare with previous studies, and failure to adequately consider the motivational aspects of the training process.

\section{Conclusions}

This study has presented evidence that distance education may provide an effective learning technique for the knowledge, skills and attitudes appropriate for the jobs of health care providers. This required adequate programme materials, welldesigned practical activities to be implemented by motivated participants, and close supervision. The educational methodology is particularly well suited to training providers in difficult to reach rural areas.
Distance learning may not be equally effective for addressing all service problems. We found, for example, that it is very difficult to make actual changes in service organisation and patient flows. Such problems frequently require ad hoc solutions based on local expertise, and probably even closer monitoring and supervision.

\section{Acknowledgement}

Claudia Aguilar provided capable assistance in data processing and analysis.

Statements on funding and competing interests

Funding. This project was conducted with support from USAID/G-CAP under Cooperative Agreement No. 520-0357-A-00-4169-00 with the Population Council, which is gratefully acknowledged.

Competing interests. None identified.

References

1 Oliveira J. Trends in distance learning: a new wave. Dev Com Rep 1988; 63: 1-4.

2 Programa Nacional de Salud Reproductiva. Guatemala: Ministerio de Salud Pública y Asistencia Social (MSPAS), 2000.

3 Central Intelligence Agency (CIA). CIA Fact Book. Washington, DC: CIA, 2003.

4 World Health Organization (WHO). Medical Eligibility Criteria for Contraceptive Use: Improving Access to Ouality Care in Family Planning (2nd edn). Geneva, Switzerland: WHO, 2000.

5 World Health Organization (WHO). Selected Practice Recommendations for Contraceptive Use. Geneva, Switzerland: WHO, 2000 .

6 Langer A. Mensajes básicos de la salud reproductiva. Mexico: Population Council, 1998

7 Solórzano J, Burkhart M. Reingenieria del modelo de atención. Guatemala: Population Council Research report: USAID/G-CAP Cooperative Agreement No. 520-0357-A-00-4169-00, 1999.

8 Vernon R, Ottolenghi E, Solórzano J, Santamarina LR, Arroyo JJ, Barrios CL. Systematic Offering of Family Planning and Reproductive Health Services in Guatemala. Mexico: Population Council, INOPAL III research report, 1997.

9 Vernon R, Foreit J. How to help clients obtain more preventive reproductive health care. Int Fam Plann Perspect 1999; 25: 200-202.

10 Burkhart M., Mendez F, Lopez F. How to Provide Direct, Safe, Barrier-free and High Quality Family Planning Services. Guatemala: Population Council Research report: USAID/G-CAP Cooperative Agreement No. 520-0357-A-00-4169-00. Guatemala: Population Council, 1999.

11 Mendez F, López F, Brambila C, Burkhart M. Screening family planning needs: an operations research project in Guatemala. BMC Int Health Hum Rights 2004; 4: 2.

12 Brambila C, López F, García-Colindres J, Donis MV. Institutionalization of Service Delivery Improvement Strategies: A Distance Learning Programme. Guatemala: Guatemala Population Council, March-October 2001.

\title{
The David Bromham Annual Memorial Award
}

David Bromham was the first Chairman of The Faculty of Family Planning and Reproductive Health Care. Sadly, halfway through his second term of office he became ill, and in 1996 he died. His loss was tragic, not only for the Faculty, but for the family planning movement in Britain and worldwide. Throughout his life, David was an energetic and inspirational man. Whilst in Leeds, he set up an assisted conception programme, which was and is one of the most successful in the world. In 1991 he set up a fertility control unit designed to provide a more accessible service for the termination of pregnancy. He also carried out an extensive programme of research and was closely involved with the British Journal of Family Planning (now the Journal of Family Planning and Reproductive Health Care).

\section{Award Criteria}

The David Bromham Memorial Award is in remembrance of a man who was happiest when deeply immersed in all that was happening within his fields of interest and who never wasted any time. The Award is not intended to be a prize for long and distinguished service, rather for a piece of work which through inspiration, innovation or energy has furthered the practice of family planning and reproductive health care in any way and any setting. It is not a research grant. Younger health professionals sometimes undervalue their achievements but they are exactly the people that David Bromham would have wished to see encouraged as this award now acknowledges.

Nominations

The award will be made either to an individual (who must be a current Diplomate or Member of the Faculty) or to a team, which could be multidisciplinary. In the latter case, the lead doctor should be a current member of the Faculty. You may nominate yourself or your team or be nominated by someone else.

Award

The award itself, which will be presented at each year's AGM, will comprise a monetary sum and inscribed memento.

Nomination Process

Nomination is by completion of a form that can be downloaded from the Faculty website at www.ffprhc.org.uk. Completed submissions must be received at the Faculty office by 10 April annually. 